\title{
Clinicopathological Study of Primary Central Nervous System Tumours - A Descriptive Study in a Tertiary Care Center Hospital of Dakshina Kannada
}

\author{
Deepak Panasseril Jayapradeepp ${ }^{1}$, Muktha R. Pai ${ }^{2}$ \\ ${ }^{1}$ Department of Pathology, MES Medical College, Perinthalmanna, Kerala, India, ${ }^{2}$ Department of Pathology, \\ AJ Institute of Medical Sciences and Research Centre, Mangalore, Karnataka, India.
}

\section{ABSTRACT}

\section{BACKGROUND}

The central nervous system (CNS) consisting of brain and spinal cord is a delicate and a complex organ. Even a minor lesion within the central nervous system can significantly affect the higher functions and the voluntary and involuntary systems of the body. The CNS tumours have become one among the leading cause of cancer death in the present days. Early diagnosis and proper grading of these tumours can significantly improve the patient outcome. This study was conducted with an objective of correlating the clinical features with histomorphological characteristics of the primary CNS tumours and to grade the primary CNS tumors based on World Health Organization (WHO) classification.

\section{METHODS}

This was a descriptive observational study. A total of 117 cases of primary CNS tumours were collected from January 2012 to June 2017 at the central diagnostic laboratory of A.J Institute of Medical Sciences and Research Centre, Mangalore belonging to the Dakshina Kannada district of Karnataka, India. Out of 117 cases, 35 cases were retrieved from the files and remaining 82 were fresh cases. The tissues were fixed in $10 \%$ buffered formalin and routinely processed. The tissue sections were stained with haematoxylin and eosin and were classified based on WHO classification. Special stain like reticulin was done in selected cases to establish the diagnosis. Patient details including the complete clinical history was collected to correlate with the histological findings.

\section{RESULTS}

Meningeal tumours were the maximum (37.6 \%) among the central nervous system tumours in present study. Clinically, most of them (40.9\%) presented with headache and seizures. The commonest clinical presentation of central nervous system tumours observed in the present study was seizures (31.6 \%). Middle cranial fossa was the preferred site for the CNS tumours (35\%). The study showed a female preponderance for CNS tumour with a male to female ratio of $1: 1.3$. The mean age for primary CNS tumours observed in the present study was 43.94 years.

\section{CONCLUSIONS}

In the present study, a systematic analysis of primary central nervous system tumour has been done giving due importance to the clinical features. The present study also showed a significant correlation with that of other studies. Despite of having modern imaging technique, the histopathological examination remains as the gold standard in diagnosing CNS tumours.

\section{KEY WORDS}

CNS Tumours, Neuroepithelial Tumours, Meningioma, Astrocytoma, Schwannoma.
Corresponding Author: Dr. Deepak P J, Panasseril House, Asamannoor P.O, Perumbavoor(Via), Ernakulam(Dist.) - 683549, Kerala, India.

E-mail: deepakpanasseril@gmail.com

DOI: $10.14260 / j e m d s / 2021 / 634$

How to Cite This Article: Jayapradeep DP, Pai MR. Clinicopathological study of primary central nervous system tumours - a descriptive study in a tertiary care center hospital of Dakshina Kannada. J Evolution Med Dent Sci 2021;10(36):3109-3114, DOI: 10.14260/jemds/2021/634

Submission 28-05-2021,

Peer Review 26-07-2021,

Acceptance 03-08-2021,

Published 00-09-2021.

Copyright (C) 2021 Deepak Panasseril Jayapradeep et al. This is an open access article distributed under Creative Commons Attribution License [Attribution 4.0 International (CC BY 4.0)] 


\section{BACKGROUND}

The CNS consist of brain and spinal cord and is composed of neurons, neuronal processes, supporting cells (glial cells) and blood vessels. The CNS is invested with meninges and is suspended in fluid, the cerebrospinal fluid (CSF) which is produced by specialized choroid plexus structures. Grossly, entire CNS is made up of grey matter and white matter. Grey matter contains neuron cell bodies while white matter contains axons. Myelin sheath provides the white appearance of the white matter. ${ }^{1}$ Central nervous system tumours accounts for $2 \%$ to $5 \%$ of all tumours in the human body. ${ }^{2}$ Among these tumours, $80 \%$ involve the brain and $20 \%$ involve the spinal cord. ${ }^{2}$ Meningioma has a significant role in the history of intracranial tumours. Other tumours disappear as the accompanying brain lyses. But the evidence of meningioma remains intact in skull. ${ }^{3}$ Hyperostosis, caused by meningioma, has been found in neolithic, Egyptian, and South American skulls. ${ }^{3}$ The presence of clinically palpable external hyperostosis was used to localize meningioma in early $19^{\text {th }}$ century. ${ }^{4}$ Neuropathology developed as a distinct discipline differently in different parts of the world. Hughlings Jackson, William Gowers, Victor Horsley and R.H. Clarke were the famous personalities in England. They combined neurophysiological and pathological techniques in order to understand diseases of the nervous system. In USA Harvey Cushing, working with Percival Bailey, established the field of neuro-oncology. ${ }^{5}$

Clinical features also play an important role in the early detection of primary CNS tumours. Brain tumours can present with a variety of clinical features. It can produce signs and symptoms of local brain invasion, compression of adjacent structures, and increased intracranial pressure (ICP). ${ }^{6}$ In order to reach at a proper diagnosis, a detailed history, comprehensive neurologic examination, and appropriate diagnostic neuroimaging studies are needed.

The first two articles dealing with magnetic resonance (MR) imaging of brain tumours was published in 1984. In the first report, T1 measurements of brain masses were done, and it showed that astrocytomas had the longest T1 and lipomas had the shortest. ${ }^{6}$ The second article contained a comparison between the computed tomography (CT) and MR imaging. It was found that very small tumours and calcifications were missed at MR imaging and the differentiation of tumours from surrounding edema was difficult.7 Pre-operative evaluation of patients by MRI or CT scan are essential for the optimal management of the patients, but definite diagnosis can be done only by the study of histological sections. ${ }^{8}$ The pathological classification of brain tumours plays an important role in planning patient management and treatment strategy. ${ }^{9} \mathrm{WHO}$ classification of brain tumours was introduced with an aim to establish a classification and grading of human tumours that is accepted and used worldwide. The first edition on the histological typing of tumours of the nervous system was published in 1979 and was edited by Zülch et al. ${ }^{10}$ Recently in 2016, WHO has modified the classification for CNS tumours. The role of the pathologist is to identify the target for the clinical team members so that they can aim their weapons upon it. ${ }^{9}$

It was found that only few studies were conducted based on clinicopathological characteristics of the primary CNS tumours. The aim of this study was histopathological diagnosis and typing of primary CNS tumours and to evaluate the clinical and pathological characteristics of primary CNS tumours.

\section{METHODS}

The present study was a descriptive observational type of study. All the samples obtained during the study period were included in the study. Inadequate biopsy material, follow up cases, post therapeutic, metastatic and recurrent tumors were excluded from the present study. The material used in this study was obtained from 117 cases of primary central nervous system tumours, received in the Department of Pathology, A J Institute of Medical Sciences, Mangalore from January 2012 to July 2017.

Three and a half years of retrospective study from January 2012 to July 2015 and two year prospective study from July 2015 to July 2017. Histopathological diagnosis of the tissue sections were done based on the WHO classification for CNS tumours.

The study was conducted after obtaining the approval from the institutional ethics committee. Paraffin embedded sections were stained with routine haematoxylin and eosin stain. Reticulin staining was done for selected cases.

\section{Statistical Analysis}

The data collected was entered in Microsoft Excel and was analysed using Statistical Package for Social Sciences software (SPSS version 20.0). The statistical results were expressed in numbers and percentages.

\section{RESULTS}

In the present study, there were 117 cases of primary central nervous system tumours. Out of these 117 cases, there were 40 cases $(34.2 \%)$ of neuroepithelial tumours, 44 cases $(37.6$ $\%$ ) of meningeal tumours and 33 cases (28.2 \%) of cranial and paraspinal nerve tumours.

Tumours of meninges were the most common CNS tumours observed (37.6\%). The least were the cranial and paraspinal nerve tumours $(28.2 \%)$

\section{Clinical Features}

\begin{tabular}{|ccc|}
\hline Clinical Features & No. of Cases & Percentage (\%) \\
Headache and vomiting & 35 & $29.9 \%$ \\
Seizures & 37 & $31.6 \%$ \\
Hearing loss & 13 & $11.11 \%$ \\
Tinnitus & 4 & $3.41 \%$ \\
Gait instability & 9 & $7.69 \%$ \\
Motor weakness & 17 & $14.52 \%$ \\
Vision disturbances & 2 & $1.7 \%$ \\
Total & $\mathbf{1 1 7}$ & $\mathbf{1 0 0} \%$ \\
\hline Table 1. Clinical Features of Central Nervous System Tumours \\
\hline
\end{tabular}

In the present study, the commonest clinical presentation for primary central nervous system tumours were seizures (31.6\%). Also, it was observed that all the patients who presented with seizures were diagnosed to have gliomas histopathologically. 


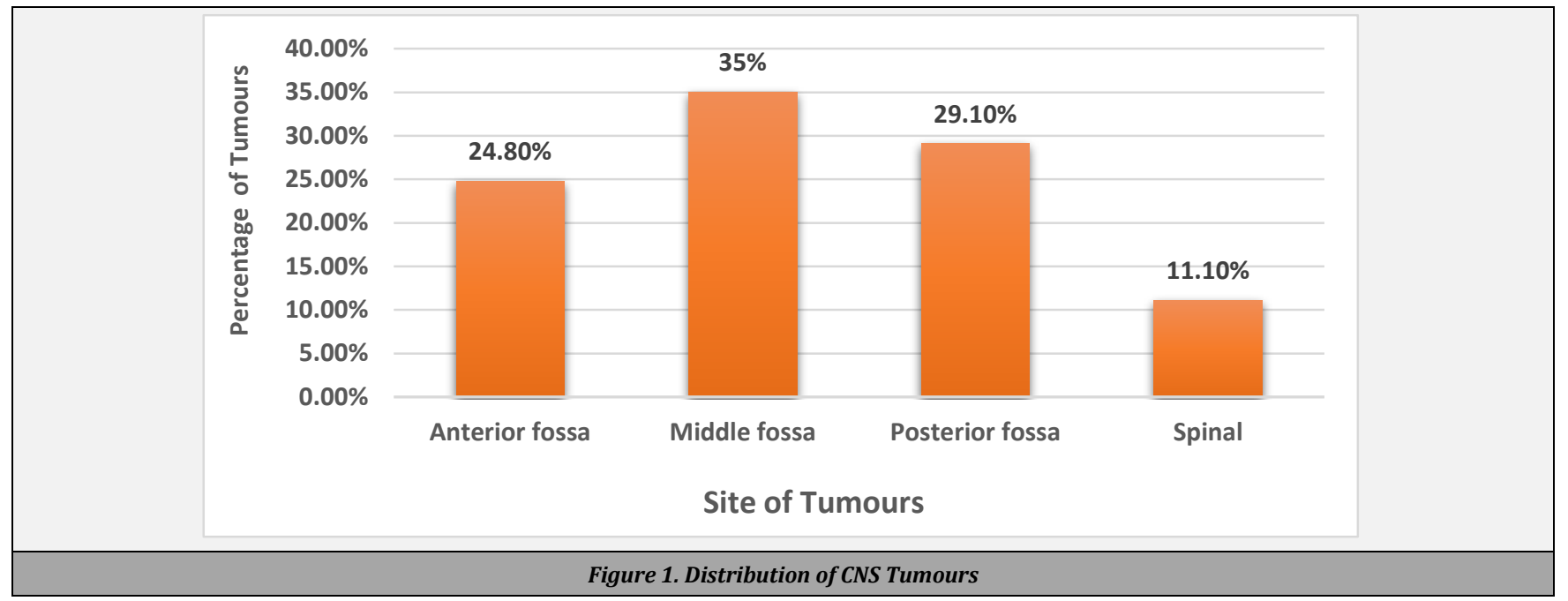

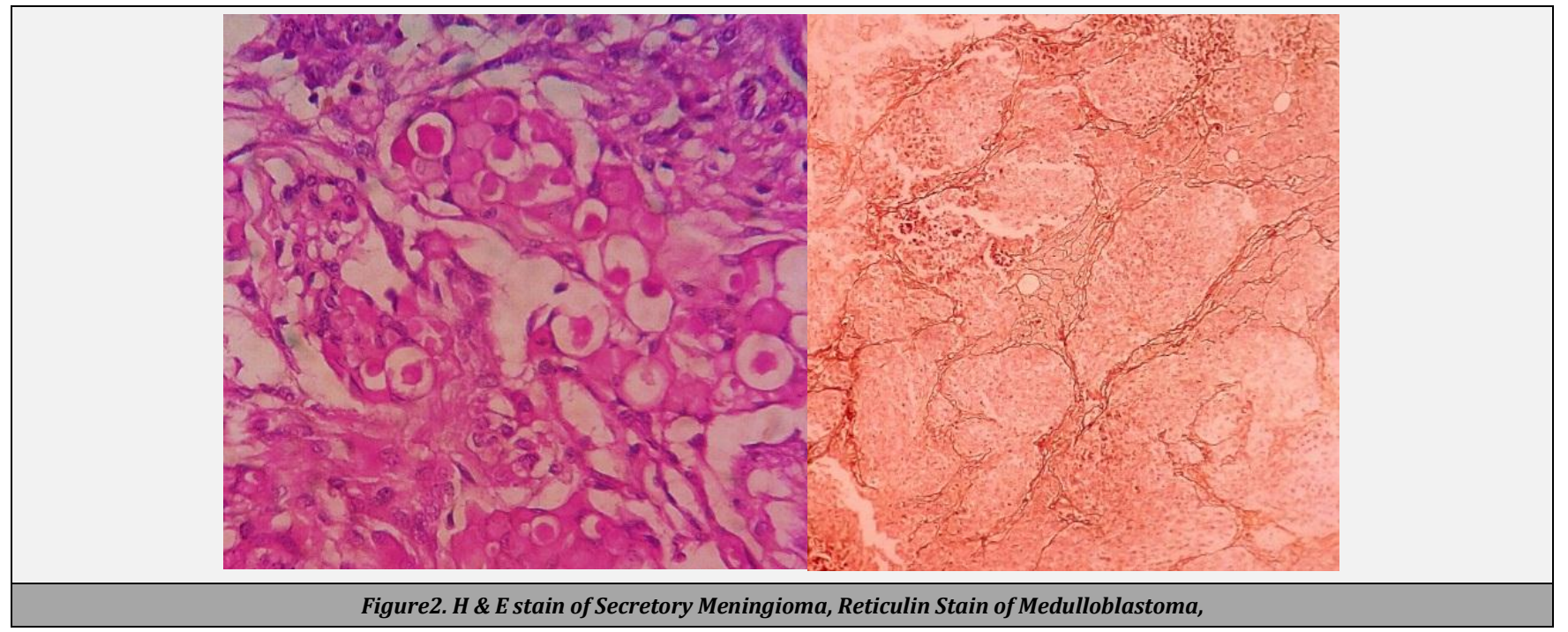

\section{Site of the Tumours}

The most preferred site for the primary central nervous system tumours were the middle cranial fossa. A total of 41 cases out of 117 representing $35 \%$ of the entire CNS tumours were seen in the middle cranial fossa (figure 1). The most common among the middle cranial fossa tumours were the astrocytoma ( $56 \%$ ), representing 23 out of the total 41 cases of middle cranial fossa tumours.

\section{Gender Distribution of Tumours}

\begin{tabular}{|ccccc|}
\hline Tumours & Male & Female & Frequency & Percentage \\
Astrocytoma & 16 & 17 & 33 & $28.2 \%$ \\
Oligodendroglioma & 0 & 2 & 2 & $1.7 \%$ \\
Ependymoma & 0 & 1 & 1 & $0.85 \%$ \\
Medulloblastoma & 2 & 0 & 2 & $1.7 \%$ \\
$\begin{array}{c}\text { Primitive neuro } \\
\text { ectodermal tumour } \\
\text { (PNET) }\end{array}$ & 1 & 0 & 1 & $0.85 \%$ \\
$\begin{array}{c}\text { Ganglioglioma } \\
\text { Meningioma }\end{array}$ & 0 & 1 & 1 & $0.85 \%$ \\
Schwannoma & 16 & 28 & 44 & $37.6 \%$ \\
Total & $\mathbf{5 0}$ & 18 & 33 & $28.2 \%$ \\
\hline \multicolumn{5}{r}{ Table 2. Gender Distribution of Tumours } \\
\hline
\end{tabular}

It was observed that the central nervous system tumours were more common in females than in males with a male to female ratio of $1: 1.3$. However, it is evident from the above table (Table 2) that, there were certain exceptions to this rule viz, medulloblastomas and primitive neuro ectodermal tumours were more common in males than in females.

\section{Age Distribution of Tumours}

In the present study, the CNS tumours have been divided into three broad categories based on the age distribution. The age group of 0 - 14 years as children, 15 - 24 years as adolescents and 25 - 80 years as adults. The following table (Table 3 ) show the frequency of distribution of various CNS tumours in these three age groups.

The maximum number of CNS tumours were observed in the age group of 25 - 80 years (90.59\%). Meningiomas were the commonest tumours observed in this age group (40.56\%).

\begin{tabular}{|cccc|}
\hline Tumours & $\begin{array}{c}\text { Age Group } \\
\mathbf{( 0 - 1 4} \\
\text { Years) }\end{array}$ & $\begin{array}{c}\text { Age Group } \\
\mathbf{( 1 5}-\mathbf{2 4} \\
\text { Years) }\end{array}$ & $\begin{array}{c}\text { Age Group } \\
\mathbf{( 2 5}-\mathbf{8 0} \\
\text { Years) }\end{array}$ \\
Astrocytoma & $1(20 \%)$ & $6(100 \%)$ & $26(24.5 \%)$ \\
Oligodendroglioma & $0(0 \%)$ & $0(0 \%)$ & $2(1.88 \%)$ \\
Ependymoma & $0(0 \%)$ & $0(0 \%)$ & $1(0.94 \%)$ \\
Medulloblastoma & $2(40 \%)$ & $0(0 \%)$ & $0(0 \%)$ \\
Primitive neuroectodermal & $1(20 \%)$ & $0(0 \%)$ & $0(0 \%)$ \\
tumour & $0(0 \%)$ & $0(0 \%)$ & $1(0.94 \%)$ \\
Ganglioglioma & $1(20 \%)$ & $0(0 \%)$ & $43(40.56 \%)$ \\
Meningioma & $0(0 \%)$ & $0(0 \%)$ & $33(31.13 \%)$ \\
Schwannoma & $\mathbf{5 ( 1 0 0 \% )}$ & $\mathbf{6 ( 1 0 0 \% )}$ & $\mathbf{1 0 6}(\mathbf{1 0 0} \%)$ \\
\hline Total & Table 3. Age Distribution \\
\hline \multicolumn{4}{c}{}
\end{tabular}




\section{Tumours of Neuroepithelial Origin}

\begin{tabular}{|c|c|c|c|c|c|}
\hline \multirow[t]{2}{*}{ Histological Type } & \multirow{2}{*}{\multicolumn{2}{|c|}{ Males Females }} & \multirow[t]{2}{*}{ Total } & \multirow{2}{*}{$\begin{array}{c}\text { Percentage } \\
\text { among } \\
\text { Intracrania } \\
\text { Tumours }\end{array}$} & \multirow{2}{*}{$\begin{array}{c}\text { Percentage } \\
\text { among } \\
\text { Neuroepithelial } \\
\text { Tumours }\end{array}$} \\
\hline & & & & & \\
\hline Astrocytoma & 16 & 17 & 33 & $28.2 \%$ & $82.5 \%$ \\
\hline Oligodendroglioma & 0 & 2 & 2 & $1.7 \%$ & $5 \%$ \\
\hline Ependymoma & 0 & 1 & 1 & $0.85 \%$ & $2.5 \%$ \\
\hline Ganglioglioma & 0 & 1 & 1 & $0.85 \%$ & $2.5 \%$ \\
\hline Medulloblastoma & 2 & 0 & 2 & $1.7 \%$ & $5 \%$ \\
\hline $\begin{array}{l}\text { Primitive neuro } \\
\text { ectodermal tumour } \\
\text { (PNET) }\end{array}$ & 1 & 0 & 1 & $0.85 \%$ & $2.5 \%$ \\
\hline Total & 19 & 21 & 40 & $34.15 \%$ & $100 \%$ \\
\hline
\end{tabular}

Among the neuroepithelial tumours, astrocytoma (82.5\%) was the commonest. Females were slightly more affected than males with a male to female ratio of $1: 1.1$.

\section{Astrocytic Tumours}

The astrocytic tumours were distributed in a wide age range starting from the first decade and were extending up to the sixth decade. Most of the astrocytoma presented with features of raised intracranial pressure. The common clinical features were headache and vomiting. Middle cranial fossa was the preferred location for astrocytoma (56\% cases). Astrocytoma were most commonly seen in the age group of 21 - 30 years with a female preponderance. Male to female ratio was $1: 1.1$. The commonest age group involved in males was the fourth decade, where as in females was the second decade. In the present study, there were 11 cases of pilocytic astrocytoma, 1 case of pilomyxoid astrocytoma, 3 cases of diffuse astrocytoma, 7 cases of fibrillary astrocytoma, 5 cases of gemistocytic astrocytoma, 2 cases of anaplastic astrocytoma and 4 cases of glioblastoma. The WHO grade 2 tumours were more common among the astrocytoma and represented 15 cases (45.45\%) out of the total 33 cases of astrocytoma. Pilocytic astrocytoma were the commonest variant observed among the astrocytoma (33.3\%). Out of the 11 cases, 2 of them were located within the cerebellum. On CT scan, the pilocytic astrocytoma presented as cystic lesions with contrast enhancing mural nodule. Histologically, they showed bipolar piloid cells, rosenthal fibres and blood vessels showing hyalinization were also seen.

\section{Oligodendroglial Tumours}

Oligodendroglioma constitutes $5 \%$ of all the neuroepithelial tumours studied. In the present study there were 2 cases of oligodendroglioma and both were seen in females. The tumour was located within the frontal lobe in both the cases. The patients presented with seizures and features of raised intracranial tension. The histological sections showed sheets of tumour tissue composed of monomorphic cells with uniform round nuclei and perinuclear halos forming honeycomb appearance. Areas of microcalcifications and the characteristic chicken wire type of vascular proliferation was also seen.

\section{Ependymal Tumours}

Ependymoma constituted $0.85 \%$ of all tumours studied and represented $2.5 \%$ of all neuroepithelial tumours. In the present study, there was a single case of tanycytic ependymoma, located within the spinal cord. It was a female patient aged 53 years and presented with weakness of both the lower limbs.

Microscopically, the tumour cells are arranged in dual zones of hyper cellularity and fibrillary process. Cellular areas are composed of rounded cells with oval nucleus having smooth contour and light and dark chromatin, arranged in rhythmic pattern. Fibrillary areas showed bundles of elongated processes with elongated nucleus having granular chromatin and resembled tanycytes, the paraventricular cells. Mitosis are sparse $0-1$ / HPF.

\section{Neuronal and Mixed Neuronal-Glial Tumours}

In the present study, neuronal and mixed neuronal-glial tumours constituted $0.85 \%$ of all primary central nervous system tumours studied. It was a single case of ganglioglioma in a 38 year old patient, presented with recurrent seizures. The tumour was located within the temporal lobe. CT scan showed a well-defined cystic lesion with intensely enhancing nodule and areas of calcification.

Microscopic examination showed a mixture of neuronal and glial cell elements. Proliferating astrocytes and oligodendrocytes were seen admixed with loose clusters of dysplastic uninucleate to multinucleate ganglion cells in a fibrillary background. Prominent network of branching capillaries with hyalinized walls and prominent endothelial cells were also seen.

\section{Embryonal Tumours}

Embryonal tumours represent $2.56 \%$ of all primary central nervous system tumours. In the present study, there were 2 cases $(1.7 \%)$ of desmoplastic medulloblastoma. All these tumours were seen in children belonging to the age group of 0 - 10 years. Both were male patients. Cerebellar vermis was the preferred location of the tumour in both the cases. They presented clinically with features of raised intracranial pressure and seizures.

There were 2 cases of desmoplastic medulloblastomas. The tumour tissue in both the cases was composed of nodular, pale islands of cells surrounded by densely packed, highly proliferative cells with hyperchromatic, pleomorphic nuclei with occasional Homer Wright rosette formation. Reticulin stain showed reticulin free pale islands surrounded by dense intercellular network of reticulin fibres (Fig 2).

The other case was that of a primitive neuroectodermal tumour and it represented $0.85 \%$ of all primary central nervous system tumours. The tumour was located within the anterior cranial fossa and presented clinically with recurrent episodes of headache. Microscopic examination showed sheets of tumour cells having hyperchromatic round nucleus with scant cytoplasm. Mitotic figures were 1 - 2 per high power field.

\section{Tumours of Meninges}

Meningiomas were the most common tumour representing $37.6 \%$ (44 cases) of all intracranial tumours studied. Clinically, headache (40.9\%) and seizures (40.9\%) were the commonest presentation. Majority (95.45\%) of the 
meningiomas were intracranial and the remaining $4.5 \%$ of tumours were spinal in location. The cerebral convexities were the preferred location (43.1\%).

Maximum number of cases (20 cases) representing 45.45 $\%$ of all meningiomas were observed in the fifth decade and showed a female predominance. Male to female ratio was 1 : 1.75. In the present study, there were 17 cases of meningothelial meningioma, 2 cases of fibroblastic meningioma, 16 cases of transitional meningioma, 1 case of psammomatous meningioma, 6 cases of angiomatous meningioma, 1 case of hemangiopericytoma and 1 case of secretory meningioma.

Meningothelial meningioma (WHO grade 1) was the commonest variant observed representing $38.63 \%$ (17 cases) of all meningiomas. Frontal convexity was the preferred location (47\%). Most common clinical presentation being seizures $(58.8 \%)$. One case of secretory meningioma (WHO grade 1) representing $2.27 \%$ of the total meningiomas was observed in the present study. It was observed in a 51 year old female patient presented with recurrent episodes of headache. The tumour was located within the temporal convexity. On microscopy, it showed cystic spaces containing periodic acid Schiff stain (PAS) positive eosinophilic secretions known as pseudopsammoma bodies (Fig 2).

\section{Cranial and Paraspinal Nerve Tumours}

In the present study, there were 21 cases of intracranial and 12 cases of paraspinal nerves. All the intracranial neurilemmomas were originating from the vestibular branch of the eighth cranial nerve (Acoustic schwannomas). The most preferred location for schwannomas hence was the cerebellopontine angle (63.6\%).

The vestibulocochlear nerve in the cerebellopontine angle was the commonest site of all intracranial schwannomas and the remaining tumours were located at the spinal cord levels.

Clinically, the cerebellopontine angle tumours mostly presented with hearing loss, gait instability, headache and tinnitus. The most common being progressive hearing loss, which was observed in $42.4 \%$ of the schwannomas. The spinal cord lesions presented with features like lower limb weakness and radicular pain.

The tumour showed female predominance with a male to female ratio of $1: 1.2$ and was most commonly seen in the age group 51 - 60 years. The tumour cells were forming two basic patterns in varying proportion as hypercellular Antoni A and hypocellular Antoni B areas. Scattered Verocay bodies and nuclear pleomorphism were noted in all the cases of acoustic schwannomas. Hyalinized blood vessels were seen in the hypocellular areas.

\section{DISCUSSION}

In the present study, 117 cases of primary central nervous system tumours were analysed based on the age, gender, clinical features and site of the tumour. The results of this study have been compared with other studies.

In the present study, meningeal tumours were more common (37.2\%) when compared to that of neuroepithelial, cranial and paraspinal nerve tumours. This was comparable with the observation done by Kanthikar et al. ${ }^{11}$ (39.47 \%) and Lee et al.12 (31.2\%), in their respective studies. The incidence of cranial and paraspinal nerve tumours were found to be higher $(28.2 \%)$ in the present study when compared with studies done by Kanthikar et al. ${ }^{11}(18.42 \%)$ and Lee et al. ${ }^{12}$ (11.1\%).

The present study showed a female predominance with a male to female ratio of $1: 1.3$, which was in contrast to few of the previously published Indian and foreign studies and was in concordance to findings of Kanthikar et al. ${ }^{11}$ and Lee et al. ${ }^{12}$

The mean age observed in the present study (43.94 years) was comparable with the study done by Masoodi et al. ${ }^{17}$ and showed a stricking similarity between both the studies (43.29 years).

In the present study, most of the tumours were intracranial in location (88.8\%) when compared with spinal tumours. The results were comparable with the studies of Zalata et al..$^{13}$ and Masoodi et al. ${ }^{17}$ with percentage of incidence being $86.7 \%$ and $86.8 \%$ respectively.

In the studies done by Masoodi et al. ${ }^{17}$ and Mondal et al. ${ }^{18}$ headache was the commonest clinical feature observed. This was in contradiction to the present study findings, in which seizures $(31.6 \%)$ were relatively more common. But the proportion of patients with seizures were found to be comparable with the present study representing $31.1 \%$ and $36.9 \%$ respectively.

Also, WHO grade 1 tumour was the commonest and represented $97.7 \%$ of the entire central nervous system tumours. In the present study, the incidence of WHO grade 1 tumour was found to be higher when compared with that of other studies, but showed a comparable incidence (92\%) with the study done by Shah et al. ${ }^{19}$

Meningiomas were the commonest brain tumours encountered in the present study. Meningiomas constitute $37.6 \%$ of all intracranial tumours and showed a comparable incidence with the study done by Kanthikar et al. ${ }^{11}$ and Lee et al. ${ }^{12}$ with percentage of incidence being $39.4 \%$ and $31.2 \%$ respectively.

Intracranial meningiomas constitute $95.45 \%$ of all the meninigiomas in the present study. The majority ( $47.7 \%$ ) of them were in the cerebral convexities which was correlating with the study done by Madabhushi et al. ${ }^{20}$ and Sujatha et al. ${ }^{21}$ Headache and seizures were the commonest clinical presentations and were in concordance with the studies of Sujatha et al. $^{22}$ and Dhanapandian et al. ${ }^{22}$

In the present study, female predominance for meningioma was noted with a male to female ratio of $1: 1.75$. The study done by Dhanapandian et al. ${ }^{22}$ and Patil et al. ${ }^{23}$ also supports a female preponderance to meningioma.

\section{CONCLUSIONS}

The present study systematically analyses 117 cases of primary central nervous system tumours over a period of five and a half years from January 2012 to July 2017, in terms of age group, sex, tissue of origin and clinical features. The study has provided an insight into the clinicopathological pattern of various central nervous system tumours. 
The treatment plan of the patient is mainly tailored based on the histopathological diagnosis. The knowledge regarding the clinical details including the radiological location of the tumours significantly helps the pathologist to narrow down the possible diagnosis.

The present study showed correlation regarding most aspects with that of other studies done in India and abroad in the recent past. The clinicopathological aspect and the role of pathologist in these times of evolution of medical science knowledge for the specific diagnosis of central nervous system tumours is also quite evident from the present study.

\section{Limitations of This Study}

One of the major limitations of the present study was the absence of molecular studies and immunohistochemistry (IHC) for analysis as recommended by the latest 2016 WHO classification for central nervous system tumours.

Data sharing statement provided by the authors is available with the full text of this article at jemds.com.

Financial or other competing interests: None.

Disclosure forms provided by the authors are available with the full text of this article at jemds.com.

\section{REFERENCES}

[1] Garman RH. Histology of the central nervous system. Toxicologic Pathology 2011;39(1):22-35.

[2] Mollah N, Baki A, Afzal N, et al. Clinical and pathological characteristics of brain tumor. BSMMU J 2010;3(2):6871.

[3] Castillo M. History and evolution of brain tumor imaging: insights through radiology. Radiology 2014;273(Suppl 2):111-25.

[4] Kerr PB, Caputy AJ, Horwitz NH. A history of cerebral localization. Neurosurg Focus 2005;18(4):e1.

[5] Richardson EP Jr, Astrom KE, Kleihues P. The development of neuropathology at the Massachusetts General Hospital and Harvard Medical School. Brain Pathol 1994;4(2):181-8.

[6] Araki T, Inouye T, Suzuki H, et al. Magnetic resonance imaging of brain tumours: measurement of $\mathrm{T} 1$ work in progress. Radiology 1984;150(1):95-8.

[7] Brant-Zawadzki M, Badami JP, Mills CM, et al. Primary intracranial tumor imaging: a comparison of magnetic resonance and CT. Radiology 1984;150(2):435-40.

[8] Patty ISH. Central Nervous System tumours - a clinicopathological study. J Dohuk Univ 2008;11(1):17380.
[9] Zu"lch KJ. Histologic typing of tumours of the central nervous system. Geneva, Switzerland: World Health Organization, 1979.

[10] Al-Hussaini M. Histology of primary brain tumours. Intech 2013: p. 145-79.

[11] Kanthikar SN, Nikumbh DB, Dravid NV. Histopathological overview of central nervous system tumours in North Maharashtra, India: a single center study. Indian Journal of Pathology and Oncology 2017;4(1):80-4.

[12] Lee CH, Jung KW, Yoo H, et al. Epidemiology of primary brain and central nervous system tumors in Korea. Journal of Korean Neurosurgical Society 2010;48(2):14552.

[13] Zalata KR, El - Tantawy DA, Abdel - Aziz A, et al. Frequency of central nervous system tumors in delta region, Egypt. Indian Journal of Pathology and Microbiology 2011;54(2):299-306.

[14] Materljan E, Materljan B, Sepcic J, et al. Epidemiology of central nervous system tumors in Labin area, Croatia, 1974-2001. Croatian Medical Journal 2004;45(2):20612.

[15] Katsura S, Suzuki J, Wada T. A statistical study of brain tumors in the neurosurgical clinics in Japan. Journal of Neurosurgery 1959;16(5):570-80.

[16] Lakshmi K, Hemalatha M, TamilArasi DS, et al. Histopathological study of spectrum of the lesions of central nervous system in a tertiary care hospital. J Evol Med \& Dent Sci 2015;4(7):1145-50.

[17] Masoodi T, Gupta RK, Singh JP, et al. Pattern of central nervous system neoplasms: a study of 106 cases. JK Practitioner 2012;17(4):42-6.

[18] Mondal S, Pradhan R, Pal S, et al. Clinicopathological pattern of brain tumors: a 3 - year study in a tertiary care hospital in India. Clinical Cancer Investigation Journal 2016;5(5):437-40.

[19] Shah S, Gonsai RN, Makwana R. Histopathological study of meningioma in civil hospital, Ahmedabad. Int J Curr Res and Rev 2013;5(3):76-82.

[20] Madabhushi V, Venkata RI, Garikaparthi S, et al. Role of immunohistochemistry in diagnosis of brain tumors: a single institutional experience. Journal of Dr. NTR University of Health Sciences 2015;4(2):103-11.

[21] Sujatha S, Geeta V, SrinivasKumar V. A 2 year study of meningiomas in correlation with squash cytology and histopathological examination. Int Arch of Integr Med 2017;4(10):137-42.

[22] Dhanapandian JS, Merla JJ. A study of meningiomas in tertiary care center in South India. IOSR - Journal of Dental and Medical Sciences 2016;15(10):7-12.

[23] Patil PR, Sondankar D. Clinicopathological study of meningioma. International Journal of Medical Research and Review 2016;4(4):592-1. 